\title{
Moving Mountains: Lessons Learned from a Campus-Wide Free Textbook Initiative in Response to a Global Pandemic
}

\author{
Eric Werth \\ Katherine Williams \\ Tyler Kroon \\ University of Pikeville
}

Abstract: Students are experiencing enormous economic precarity as a result of COVID-19. Reports indicate that those hardest hit by job loss due to the coronavirus are of lower income (Beer, 2020). While economic recovery is underway for more affluent workers, the same cannot be said for those toward the bottom of the wage scale, particularly underserved populations (Long, 2020). The University of Pikeville (UPIKE) recognizes the impact that financial inequities have on our institution's most vulnerable populations. In April 2020 the institution decided to convert all classes to free materials by the start of the Fall 2020 semester. This article describes our research methods in seeking out appropriate free material and how we guided faculty in developing their own knowledge in search strategies; details the process we established for faculty to apply for funding when appropriate materials could not be found; and shares the lessons we learned.

Keywords: Open Educational Resources, faculty development, free course materials

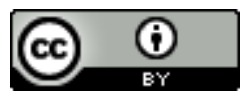

This is an Open Access article distributed under the terms of the Creative Commons Attribution 4.0 International License (http://creativecommons.org/licenses/by/4.0), which permits unrestricted use, distribution, and reproduction in any medium, provided the original work is properly cited. 


\section{Climbing the Mountain: Faculty and the OER Search Process}

After learning of the plan to make all course materials freely available to UPIKE students, representatives from the library and professional development collaborated to develop procedures for assisting faculty with the transition to Open Educational Resources (OER). We settled on two main research methods for finding material: searching library resources to which members of our university already have access, and scouring the internet for Open Educational Resources (OER) from reputable sources.

We used keywords gleaned from the course title and syllabus as well as our own expertise to conduct multiple searches, eventually curating a list of possibilities. From library resources we generally recommended eBooks licensed with 'unlimited user access.' However, we also encouraged professors to incorporate supplementary library materials such as journal articles, data sets, and videos into their courses. Most of the successful library searches stemmed from our collection of eBooks provided through the EBSCOhost and JSTOR databases.

Simultaneously, we sought relevant OER or materials that are free to access online for faculty. When describing the difference between these to our faculty, we emphasized that OERs are materials that are specifically licensed under a Creative Commons license (though openness may vary based on the license selected) while free-to-access materials may still fall under copyright and they must consider the practice of fair use when considering them. During this process, we navigated a multitude of search engines and OER providers to make sure we were comprehensive in our breadth and depth. George Mason University's Mason OER Metafinder proved especially helpful in these forays, allowing us to conduct a single search that probed multiple sites. We also explored widely-recognized OER providers directly, including OpenStax, Open Textbook Library, OER Commons, BC Campus OpenEd, 
and LibreTexts. When searching these sites, we used a combination of keyword and browse functions to find potentially valuable resources, and then added them to the above-mentioned list. During this phase, we also broadened our searches to include sites indexed on the web that may not be licensed under Creative Commons but could be directly linked to from our learning management system (LMS), Canvas. Recognizing that copyright law must be upheld, we encouraged faculty to think critically about how fair use and spontaneity worked in conjunction with materials they could access without hitting a paywall but that still fell under copyright (e.g.: an article from the New York Times website). In situations where materials were copyrighted but freely accessible we emphasized the value of reaching out to the copyright holder or using direct linking rather than downloading or printing a copy of the page and uploading that to the LMS. After this list was compiled, we sent it to the appropriate faculty members for them to determine if any of those options were suitable replacements for their previous for-cost materials.

In addition to completing research on behalf of faculty, we empowered them to search independently by curating resources that provided a roadmap to follow. Professional development staff designed an Open Educational Resources Website, and one of the librarians developed an Open Educational Resources LibGuide to organize and disseminate this information. Both of these resources included various OER sites, provided links for accessing those sources, and offered a short description about the content users could expect to find in each. This saved faculty time by pointing out which resources were more likely to have content related to their subject areas (e.g.: LibreTexts has a plethora of material on nursing and the sciences but not much in the humanities, while Project Gutenberg is better for older humanities material in the Public Domain). We also hosted faculty workshops where we demonstrated how to use these resources, discussed copyright issues, and Journal of New Librarianship, 6 (2021) pp. 41-48 10.21173/newlibs/10/5 
described how to effectively incorporate library materials, OER, and free online resources into courses via Canvas. As a result of this multifaceted approach, we noticed an increase in the number of professors who conducted independent research and discovered relevant material to use in their classes rather than relying on our team to do the searching for them.

In situations where none of the material found initially was deemed sufficient, we would ask for feedback on what was lacking and repeat the research process a second time, using that feedback as guidance. If, following this iterative process, we were unable to locate suitable free and open material, we encouraged faculty to request funding for a for-cost textbook.

\section{The Mountain has a Cliff Face: Funding Faculty When OER/Library Material Doesn't Work}

It became apparent early in the transition to free materials that supplying faculty a means to request funding for paid publisher texts was going to be vital in the initiative to provide resources available to students at no additional costs. The University Provost made available a $\$ 50,000$ fund (from lack of travel during COVID) per semester that could be used to purchase textbooks, particularly in upperdivision and special topic courses. It should be noted that the entirety of the fund was not spent each semester. In order to develop a process that was equitable for faculty, guidance was issued that clearly outlined the steps required to apply for commercial materials.

In instances where faculty could not find existing OER or library resources, faculty were able to complete a funding application. The application detailed the cost of the book, a secondary book when more than one option was possible, the rationale from the faculty member as to why no free alternatives sufficed, and an overview of research by a member of the library or professional development team who assisted the instructor. This form was first submitted to their division chair and then the college dean. 
Provided that both of these individuals approved, the application was forwarded to an existing committee to determine funding priority.

The University determined that the most appropriate group to ultimately decide which applications were funded was the faculty executive committee of the undergraduate college, consisting of faculty representatives from the divisions within the undergraduate college and the undergraduate faculty chair. In doing so, a larger group of individuals were involved in allocating funds for purchasing commercial materials. The executive faculty committee met three times over the summer of 2020 to determine funding. An assessment rubric was provided by the executive faculty chair which asked committee members to consider cost, number of students, and whether the material had long-term purchasing access. When possible, funding was granted to provide unlimited user access licenses of materials for the library in a digital format.

The professional development and library team was made available to the faculty executive committee on an ex-officio basis. This was done to clarify search processes for committee members and, on a few occasions, verify a collaborative search had been completed. While funding was not denied outright if searching was done without professional development or library involvement, in these instances faculty were asked to work with a search team member and resubmit for the next committee meeting. Over the two and a half month funding period, a majority of the applications were completed correctly and most of the funds were allocated. A new round of funding opened in late fall for the Spring 2021 semester.

\section{On Belay!: Issues and Mitigations}

Movement by faculty to OER, library resources, or other freely accessible online materials and the issues that may arise during such a transition have been previously documented. A recent report 
on OER states, "Increased adoption of OER is hampered by the fact that the majority of faculty are unaware that it even exists" (Spilovoy et al., 2020, p.9). While indicating that OER awareness and adoption are on the rise, these authors go on to state, "Among the faculty that are aware of OER, the time and effort required to find OER materials appropriate to their needs remains far greater than that required to select commercial alternatives" (Spilovoy et al., 2020, p.9). Their research, surveying faculty and department chairs nationally, suggests that it will be 2025 before half of faculty are even aware of OER and licensing at U.S. higher education institutions of all classifications (Spilovoy et al., 2020). Other implementation issues described in the literature include lack of knowledge regarding where to find OER, training, concerns about quality, technology-related problems, lack of institutional support, and confusion around legal use of resources (Bliss et al., 2013; Cox \& Trotter, 2017; Jhangiani, 2016; Padhi, 2018; Taylor \& Taylor, 2018).

The initiative at UPIKE is different from many of those described in the literature which are often incentivized through grants or conducted at the programmatic level. Movement to resources free to students was not optional at UPIKE, and all classes at the 4-year liberal arts institution had to meet this requirement. As a result, our experience not only represents that of faculty who had chosen to move to OER or those in high-enrollment courses where efforts have been made to create OER and supplemental resources, but all instructors in all classes at all levels. We experienced challenges and developed mitigation strategies that will be beneficial to others as textbook affordability efforts evolve.

The following are challenges that the library and professional development staff identified in working with faculty to move to alternatives free to students from paid textbooks. Included with each are considerations for ameliorating the identified issue. 


\section{Challenge:}

Faculty seek a single book that covers the same material in the same order as the commercial book they used previously.

Mitigation Strategy: Discuss with faculty the objectives they cover in class and whether every topic covered in their previous book is essential information. Explore the potential for using several resources and linking to these directly in the learning content for that week as well as the possibility of making edits to OER to fill in perceived gaps. Also, discuss that in some instances primary sources may increase potential for student learning.

\section{Challenge:}

Faculty are not familiar with the variety of resources available so they report checking one or two sites and leave with the impression that no adequate free resources exist.

Mitigation Strategy: Create an institutional website (e.g.: Open Educational Resources Website) and/or LibGuides (e.g.: Open Educational Resources LibGuide; Copyright \& Fair Use LibGuide) providing simplified guidance to help faculty seeking information on available resources. Ask faculty for a copy of their syllabus with learning objectives, and the material that was covered in their previous book, so staff can better work one-on-one with them to find possible alternatives.

\section{Challenge:}

Faculty expressed that a particular book is needed to prepare students for professional examinations (e.g.: pre-med, pre-law, nursing, education).

Mitigation Strategy: Assess these needs on a course-by-course basis with faculty. At times we found OER covered large parts or all of the necessary information and could be used as a suitable 
alternative. There were situations where a particular commercial book was designed to align with external accreditation standards (e.g.: CAEP for teacher preparation), ensuring required information was covered. While material could be developed over time to align to these standards, the idea of quickly finding alternatives specifically designed to meet accreditation requirements was daunting. Having a funding application was an important mitigation strategy in these situations. eBooks were added to our collection when possible to ensure perpetual use for institutional expenditure efficiency. In these instances, we attempted to obtain unlimited user access but, in some circumstances, we purchased sufficient licenses to cover enrollment in a course.

\section{Challenge:}

Some faculty delayed exploring free options fully until late in the course development process

discovering that only part of the book is provided free, supplemental resources they expected are not provided, or students cannot access the text freely.

Mitigation Strategy: We found proactive professional development is key in these situations. Make faculty aware of potential pitfalls and encourage them to look into material fully as opposed to making a quick determination that an option will or will not work. As a training item, alert faculty that some materials may appear free through a web browser search but have access caveats that impede student use.

\section{Challenge:}

Faculty who are willing to look for alternatives, but who have skill gaps that hamper their efforts. This may include those with limited familiarity regarding free options, instructors who have never had to select a textbook for a class, those who do not have course objectives articulated clearly, and faculty 
who have always used supplemental publisher content so are unaware of how to create these resources or find alternatives.

Mitigation Strategy: Resources to assist in these situations can be provided on institutional websites and library guides. However, we found group training sessions and one-on-one assistance to be key in overcoming obstacles. Consider web conferencing and screen sharing with faculty as well as conversing through email to meet more individual needs that arise. At UPIKE, a great deal of personnel time was spent providing one-on-one, on-demand assistance.

\section{Challenge:}

Faculty who do not attend professional development sessions miss vital information on searching processes and structures for working with library and professional development staff in material seeking. As a result they may encounter technical and knowledge gaps that waste their time and cause frustration.

Mitigation Strategy: We used frequent communication to help mitigate these issues. Let faculty know that if they encounter any barriers, they are encouraged to seek one-on-one assistance before becoming frustrated. In addition, collaboration with and support from academic leadership and upper administration can help bolster the importance of training attendance and the benefit it provides both faculty and students.

\section{Conclusion}

Bliss and Smith (2017) trace back the early years of OER to the mid-1990s. Nearly 25 years later, under $50 \%$ of faculty are currently aware of OER and licensing (Spilovoy et al., 2020). Awareness has been identified as the main obstacle to instructor use of open teaching practices (Nascimbeni \& 
Burgos, 2016). This is not surprising as faculty resistance to change is multi-faceted and has been identified since at least the 1970s (Tagg, 2012). Considering this pace and the growing demand to lower the cost of college for students, we believe that in the future we will see more efforts dictating rather than incentivizing the use of materials free to students. In fact, according to SPARC, to date more than half of all U.S. states have considered OER legislation (SPARC, n.d.). The experience of those at the University of Pikeville can help inform administrators, librarians, and faculty development personnel who are part of such second-tier initiatives.

While research conducted with our faculty indicates a tepid reception to mandatory free material use, the same cannot be said of students. A survey conducted at the end of the first semester of UPIKE's initiative indicated that nearly $62 \%$ of students felt that having free textbooks increased their engagement with course materials and over $65 \%$ believed it improved their performance in class (an additional $16.2 \%$ and $20.6 \%$ respectively were neutral). Students indicated that the initiative not only relieved stress, but made it easier to access materials, which they viewed as a social justice issue, echoing research by Jenkins et al. (2020). There were a few areas where students ran into difficulty. Primarily this was reported by those who had trouble locating links to resources within the institution's learning management system and individuals who wished to print full copies of all of their electronic textbooks. Nearly $43 \%$ of students, though, indicated that they had no trouble with the move to free and primarily electronic course materials.

The students' overwhelmingly positive responses prompted UPIKE to continue with the nocost course materials initiative. Faculty feedback emphasized the need for the continuance of the textbook funding program. For Spring 2021 an additional librarian was assigned to help faculty find suitable resources and vet funding applications, as reflection from fall indicated more support was Journal of New Librarianship, 6(2021) pp. 41-48 10.21173/newlibs/10/5 
needed. In addition, an attempt was made to over-communicate with instructors, keeping them updated on important deadlines far in advance as well as providing information on challenges faced in the fall and how these could be proactively addressed.

Although textbook affordability concerns existed globally prior to the emergence of COVID-19, the virus has had a dramatic impact on individual and family finances (Martin et al., 2020).

Unfortunately, after years of efforts to ameliorate economic insecurities impacting student success and well-being, we are now facing societal dynamics that threaten to widen the very gaps we were attempting to close. At the University of Pikeville, we discovered that meaningful systemic change can occur rapidly if all campus constituents work collaboratively and with the best interest of students in mind. We look forward to continuing this initiative and providing students with the peace of mind knowing that regardless of their economic situation, they will have access to the material they need to thrive.

\section{References}

Beer, T. (2020, May 14). COVID-19 fallout: Lower-income earners hit hardest by job losses. Forbes. https://www.forbes.com/sites/tommybeer/2020/05/14/covid-19-fallout-lower-income-earnershit-hardest-by-job-losses/\#774bf4f35d89

Bliss, T., Robinson, T., Hilton, J. \& Wiley, D. (2013). An OER COUP: College teacher and student perceptions of Open Educational Resources. Journal of Interactive Media in Education. 2013(1), p.Art. 4. https://doi.org/10.5334/2013-04

Journal of New Librarianship, 6 (2021) pp. 41-48 10.21173/newlibs/10/5 
Bliss, T. \& Smith, M. (2017). A brief history of open educational resources. In R. Jhangiani \& R. BiswasDiener. (Eds.), Open: The philosophy and practices that are revolutionizing education and science (pp. 9-27). Ubiquity Press. https://doi.org/10.5334/bbc.b.

Cox, G., \& Trotter, H. (2017). An OER framework, heuristic and lens: Tools for understanding lecturers' adoption of OER. Open Praxis, 9(2), 151-171. https://doi.org/10.5944/openpraxis.9.2.571

Flaherty, C. (2016, February 10). Professors can learn to be more effective instructors. Inside Higher Ed. https://www.insidehighered.com/news/2016/02/10/new-study-suggests-faculty-developmenthas-demonstrable-impact-student-learning

Jenkins, J., Sánchez, L., Schraedley, M., Hannans, J., Navick, N. and Young, J. (2020). Textbook broke: Textbook affordability as a social justice issue. Journal of Interactive Media in Education, 2020(1), 3. http://doi.org/10.5334/jime.549

Jhangiani, R., Pitt, R., Hendricks, C., Key, J., \& Lalonde, C. (2016). Exploring faculty use of open educational resources at British Columbia post-secondary institutions. BCcampus Research Report. BCcampus. https://bccampus.ca/2016/01/27/exploring-faculty-use-of-openeducational-resources-in-b-c-post-secondary-institutions/

Long, H. (2020, August 13). The recession is over for the rich, but the working class is far from recovered. The Washington Post. https://www.washingtonpost.com/business/2020/08/13/recession-isover-rich-working-class-is-far-recovered/

Martin, A., Markhvida, M., Hallegatte, S. \& Walsh, B. (2020). Socio-economic impacts of COVID-19 on household Consumption and poverty. Economics of Disasters and Climate Change, 4, 453-479 (2020). https://doi.org/10.1007/s41885-020-00070-3 
Nascimbeni, F., \& Burgos, D. (2016). In Search for the Open Educator: Proposal of a Definition and a Framework to Increase Openness Adoption Among University Educators. International Review of Research in Open \& Distance Learning, 1766), 1-17. https://doi.org/10.19173/irrodl.v17i6.2736

Padhi, N. (2018). Acceptance and usability of OER in India: An investigation using UTAUT Model. Open Praxis, 10(1), 55-65. https://doi.org/10.5944/openpraxis.10.1.623

SPARC. (n.d.). State policy tracking. https://sparcopen.org/our-work/state-policy-tracking/

Spilovoy, T., Seaman, J. \& Ralph, N. (2020). The impact of OER initiatives on faculty selection of classroom materials. https://www.onlinelearningsurvey.com/reports/impactofoerinitiatives.pdf

Tagg, J. (2012, January/February). Why does the faculty resist change? Change, 44(1), 6-15. https://doi.org/10.1080/00091383.2012.635987

Taylor, C. \& Taylor, M. (2018). I'm never doing this again!: Identifying and solving faculty challenges in adoption of open educational resources. Online Journal of Distance Learning Administration, 21(2). https://www.westga.edu/ distance/ojdla/summer212/taylor taylor 212.html 